\title{
A FRENTE PARLAMENTAR EVANGÉLICA E OS DIREITOS SEXUAIS E REPRODUTIVOS: AMEAÇAS À LAICIDADE NO BRASIL CONTEMPORÂNEO*
}

\author{
Tainah Biela Dias**
}

\begin{abstract}
RESUMO
A recente visibilidade da atuação política de parlamentares que compõem a Frente Parlamentar Evangélica (FPE) no Congresso Nacional tem sido fundamental para a compreensão de como se constrói a laicidade brasileira na contemporaneidade, sobretudo a partir do pleito eleitoral de 2010 e especificamente por conta de seu combate à ampliação dos direitos sexuais e reprodutivos. Tendo isto em vista, o intuito deste artigo é demonstrar como as questões de gênero são centrais nos debates sobre laicidade no Brasil, na medida em que entendemos que o respeito à laicidade é fundamental para o aprofundamento da democracia e para a garantia dos direitos das chamadas minorias sexuais e de gênero.

Palavras-chave: Laicidade. Gênero. Direitos Sexuais. Direitos Reprodutivos. Democracia.
\end{abstract}

\begin{abstract}
The recent visibility of the political performance of members of the Evangelical Parliamentary Front (EPF) in the National Congress has been fundamental for understanding how Brazilian secularism is built in contemporary times, especially as a result of the 2010 elections and specifically because of their struggle against the enlargement of
\end{abstract}

* O presente artigo reúne alguns fragmentos que compuseram a minha dissertação de Mestrado, intitulada Sobre Religião, Estado Laico e Cidadania LGBT+: A Frente Parlamentar Evangélica e a Defesa da Verdade sobre a Família defendida e aprovada em 22 de Março de 2017 na Universidade Metodista de São Paulo, sob orientação da Profa. Dra. Sandra Duarte de Souza.

** Doutoranda do Programa de Pós-Graduação em Ciências da Religião da Universidade Metodista de São Paulo (UMESP). Mestra em Ciências da Religião pela Universidade Metodista de São Paulo (UMESP). Membro do Grupo de Estudos de Gênero e Religião Mandrágora/NETMAL. Bacharela e licenciada em Ciências Sociais pela Pontifícia Universidade Católica de Campinas (PUC-Campinas). 
sexual and reproductive rights. With this in mind, the purpose of this article is to demonstrate how gender issues are central to the debates about secularity in Brazil, insofar as we understand that respect for secularity is fundamental for the deepening of democracy and for the guarantee of rights of the so-called sexual and gender minorities. Keywords: Secularism. Gender. Sexual Rights. Reproductive Rights. Democracy.

\section{RESUMÉN}

La reciente visibilidad de la actuación política de parlamentarios que componen el Frente Parlamentario Evangélico (FPE) en el Congreso Nacional ha sido fundamental para la comprensión de cómo se construye la laicidad brasileña en la contemporaneidad, sobre todo a partir de los comicios electorales de 2010, sobre todo por su cuenta lucha contra la ampliación de los derechos sexuales y reproductivos. En este sentido, el propósito de este artículo es demostrar cómo las cuestiones de género son centrales en los debates sobre laicidad en Brasil, en la medida en que entendemos que el respeto a la laicidad es fundamental para la profundización de la democracia y para la garantía de los derechos sexuales y reproductivos.

Palabras clave: Laicidad. Género. Derechos Sexuales. Derechos Reproductivos. Democracia.

\section{INTRODUÇÃO}

O presente artigo almeja realizar uma discussão acerca de como as questões de gênero e sexualidades têm tensionado e, de certa forma, moldado os debates a respeito da laicidade no Brasil contemporâneo. A visibilidade mais recente da atuação de parlamentares que se autodeclaram religiosos e o seu combate à ampliação dos direitos reprodutivos das mulheres e dos direitos sexuais da população LGBTIQ ${ }^{1}$ têm sido centrais para os debates em torno da laicidade, na medida em que pensamos que o respeito aos princípios laicos é fundamental para o aprofundamento da democracia e para a garantia de direitos de cidadania de minorias estigmatizadas e que têm seus direitos ainda negados.

Para a realização deste artigo, a metodologia utilizada foi pesquisa bibliográfica e documental, a partir do acesso de livros, revistas científicas e textos acadêmicos que versam sobre temáticas como laicidade,

A sigla se refere a Lésbicas, Gays, Bissexuais, Travestis, Transexuais, Intersex e Queer. 
democracia, religião e política, religiões e sexualidades, e também de discussões que tratam especificamente do caso brasileiro e da forma como a atuação da $\mathrm{FPE}^{2}$ tem provocado tensionamentos nas relações entre religião e política.

Assim, num primeiro momento, nos concentraremos em uma discussão mais conceitual acerca do tema da laicidade, suas aproximações e distanciamentos em relação ao conceito de secularização e as possibilidades de articulação desse conceito com a luta por direitos de cidadania.

Num segundo momento, o debate é realizado em torno das formas como têm sido construída a laicidade brasileira por meio da atuação dos parlamentares evangélicos que compõem a FPE e da forma como se colocam contrários à ampliação dos direitos sexuais e reprodutivos, seja em campanhas eleitorais ou por intermédio de sua atividade legislativa na Câmara dos Deputados, e também por meio da proposição de Projetos de Lei e Projetos de Decreto Legislativo, com o objetivo de demonstrar como as questões de gênero pautam os debates acerca da laicidade em nosso país.

\section{PARA COMEÇO DE CONVERSA: ALGUMAS REFLEXÕES SOBRE O CONCEITO DE LAICIDADE}

É muito comum que, quando falemos em laicidade, venha à mente outro conceito caro às Ciências Sociais e às Ciências da Religião de forma geral. Refiro-me aqui ao conceito de secularização, que protagonizou os holofotes das discussões desse campo de conhecimento no final do século XX e início do século XXI.

Ora, embora não seja possível tomar secularização como simples sinônimo daquilo que se entende por laicidade, os conceitos se associam quando nos referimos ao processo de racionalização que culmina na perda de influência da religião sobre as demais esferas da vida social, a partir da ideia weberiana de autonomização relativa das esferas enquanto uma consequência de um processo de racionalização que se origina no próprio interior do protestantismo, no que concerne à rejeição dos meios mágicos de salvação. Da mesma forma que o capitalismo moderno

Frente Parlamentar Evangélica. 
autonomiza-se da lógica teológica ascética e intramundana característica da ética protestante (Max WEBER, 2004), Weber salienta que, no decorrer desse processo, "os valores do mundo foram racionalizados e sublimados em termos de suas próprias leis" (Max WEBER, 1982, p. 379). Nesse sentido, entendemos que o processo de racionalização que dá autonomia relativa às esferas de valor é resultado de um processo de perda de influência da religião, ou seja, do processo de secularização.

Corroborando, em um primeiro momento, com Max Weber, Peter Berger faz alusão ao processo de secularização como "o processo pelo qual setores da sociedade e da cultura são subtraídos à dominação das instituições e símbolos religiosos" (Peter L. BERGER, 1985, p. 119). A despeito de recente texto do mesmo autor que revê suas contribuições referentes ao paradigma da secularização, este diz estar ocorrendo um processo de dessecularização (Peter L. BERGER, 2000), Cecília Loreto Mariz afirma, em comentário ao texto de Berger:

Apesar de afirmar que a teoria da secularização está errada, Berger não nega que a modernidade secularize em alguma medida, e que um processo de secularização e seus efeitos tenham sido frequentemente observados. O que Berger nega, não é o processo de secularização em si, mas a crença de que a modernidade vá necessariamente gerar o declínio da religião como um todo nos diferentes níveis, tanto social quanto individual (Cecília Loreto MARIZ, 2000, p. 27).

Utilizando a perspectiva ressaltada por Cecília Mariz, é necessário salientar que não existe qualquer incompatibilidade entre a efervescência religiosa identificada por Berger com o termo dessecularização, e o processo de secularização em si, que denota a perda do monopólio religioso enquanto produtor de sentido e a emancipação relativa de outras esferas que não estão mais sob a sua influência. É nessa perspectiva que, aqui, retomamos uma discussão essencial daquilo que pode fornecer subsídios para a discussão de secularização e laicidade, que interessa especificamente aos propósitos deste artigo.

Analisando as aparições do termo secularização na sociologia de Max Weber, Antônio Flávio Pierucci (1998) identifica o maior número de aparições desse conceito na sociologia do direito weberiana, momento 
no qual o autor discutiu o processo de racionalização do direito canônico do direito formal exercido por um corpo de juristas especializados. Esse processo marca, então, a autonomização do direito dos poderes teocráticos (Max WEBER, 1999). Ainda que em um primeiro momento não fique evidente quais as consequências desse processo, suas vantagens são salientadas por Pierucci (1998), na medida em que este, em acordo com Max Weber, considera esse processo que seculariza o direito como um happy end. Dessa forma, o autor afirma que:

[...] as leis, não sendo mais consideradas sagradas nem dadas, podem a partir de agora ser legitimamente modificadas, reformuladas e até trocadas. Elas são, com tudo o que isto implica de maturidade e emancipação genericamente humanas, revisáveis (Antônio Flávio PIERUCCl, 1998, p. 17, grifo do autor).

As conclusões de Pierucci nos fazem perceber como os processos de secularização e laicidade, embora se refiram à autonomização de diferentes aspectos da vida social e política em relação ao domínio exclusivo da religião, estariam intimamente imbricados. Vale ainda a distinção realizada por Jean Baubérot e Micheline Milot (2011), pois, se a secularização diz respeito aos processos sociais e culturais de perda de ingerência da religião, a laicidade, por sua vez, refere-se ao ordenamento jurídico-político que, como esfera secularizada, estabelece relações de negociação com o religioso (Jean BAUBÉROT; Micheline MILOT, 2011). Nessa perspectiva, pensar em laicidade é muito mais abrangente do que definir o conceito como a mera separação entre Estado e as religiões hegemônicas de contextos específicos. De forma a explicitar melhor a amplitude daquilo que a laicidade engloba, os autores estabelecem quatro aspectos que consideram como princípios fundamentais da laicidade. Em suas palavras:

Para fazer com que o conceito de laicidade seja mais operativo para analisar os diversos regimes de gestão da diversidade religiosa, parece ser necessário tomar quatro princípios inter-relacionados entre si. Os dois primeiros referem-se à tolerância, e têm sido gradualmente convertidos em lei, ou seja, a liberdade de consciência e de religião, e sua extensão necessária na garantia de igualdade; em seguida, 
ambos princípios de desenvolvimento de políticas que promovam sua implementação, a separação [entre Estado e confissões religiosas] e a neutralidade [do Estado em matéria religiosa] (Jean BAUBÉROT; Micheline MILOT, 2011, p. 80, tradução livre). ${ }^{3}$

Ao pensar a laicidade, procuramos entendê-la como formas de arranjos políticos que nos permitem perceber como se configuram as relações entre Estado e religião nos mais diversos países (Emerson GIUMBELLI, 2013). Na medida em que sabemos que esses arranjos políticos se estabelecem de diferentes formas a utilização de laicidades, no plural (Néstor da COSTA, 2006; Micheline MILOT, 2009; Jean BAUBÉROT, Micheline MILOT, 2011), contempla de melhor forma a discussão que se propõe.

Baubérot e Milot (2011) trabalham com seis tipos ideais de laicidade: a laicidade separatista, a laicidade autoritária, a laicidade anticlerical, a laicidade de fé cívica, a laicidade de reconhecimento e, por fim, a laicidade de colaboração (Jean BAUBÉROT; Micheline MILOT, 2011). Na concepção dos autores, "a tipologia de laicidade parece, portanto, útil para identificar essas [diferentes] concepções de laicidade que nos fazem lembrar [...] que não existe algo como uma 'essência' da laicidade" (Jean BAUBÉROT; Micheline MILOT, 2011, p. 90). Desse modo, os tipos ideais nos servem para evitar possíveis julgamentos valorativos em relação às diferentes formas que a laicidade se manifesta em contextos específicos. Além disso, possibilita análises comparativas e auxilia na percepção das próprias transformações dos arranjos políticos da laicidade que se estabelecem, dentro de um mesmo contexto, ao longo das conjunturas sociais. Isso é evidenciado pelos autores, quando salientam:

Afin de rendre la notion de laïcité la plus opératoire possible pour analyser les régimes d'aménagement de la diversité religieuse, il nous paraît nécessaire de tenir compte de ces quatre principes interdépendants qui s'articulent entre eux. Les deux principes relatifs à la tolérance qui ont graduellement été trauits dans le droit, la liberté de conscience et de religion et son prolongement nécessaire dans l'égalité, puis les deux principes d'aménagement politique qui favorisent leus concrétisation, la séparation et la neutralité (Jean BAUBÉROT; Micheline MILOT, 2011, p. 80).

$4 \quad[. .$.$] Une typologie de la laïcité nous paraît donc utile pour repérer ces conceptions de la laïcité$ qui nous rappellent, si besoin est, qu'il n'esxiste pas quelque chose comme une << essence 〉> de la laiïcité citação (Jean BAUBÉROT; Micheline MILOT, 2011, p. 90). 
Na realidade empírica, de acordo com as áreas, as épocas, as circunstâncias geopolíticas, os períodos de alguns e os medos de outros, a representação dominante dos grandes princípios democráticos, também projetos políticos em competição - em suma, uma vasta gama de parâmetros - um Estado ou segmentos da sociedade podem estar relacionados, predominantemente, a um determinado tipo de laicidade e/ou promover uma mistura de vários tipos (Jean BAUBÉROT; Micheline MILOT, 2011, p. 117). ${ }^{5}$

Apesar das evidentes limitações no estabelecimento de modelos típico-ideais de laicidade, concordamos com o fato de que tal tipologia possa ser empregada como recurso metodológico com o intuito de facilitar análises panorâmicas e comparativas, além de mostrar a dinamicidade inerente aos processos de construção da laicidade. Ainda assim, reiteramos que não se deve utilizá-los com o intuito de estabelecer julgamentos valorativos que buscam classificar melhores ou piores arranjos políticos de laicidade. Aqui está a importância de enfatizar o propósito unicamente analítico dos tipos ideais para melhor percepção das laicidades, considerando-as como processos que se inventam e reinventam de diferentes formas a depender das conjunturas histórica, política, social e cultural.

Entretanto, há outros elementos que consideramos fundamentais e que são importantes de se pontuar, na medida em que consideramos que a laicidade possui íntima relação com o conceito de cidadania. Isso também fica evidente na Declaração Universal da Laicidade no Século $\mathrm{XXI}^{6}$, elaborada por Jean Baubérot, Micheline Milot e Roberto Blancarte que, entre outras coisas, versa sobre a laicidade como princípio fundamental do Estado Democrático de Direito.

Dans la réalité empirique, suivant les domaines, les époques, les conjonctures géopolitiques, les requêtes des uns, les craintes ressenties par les autres, la représentation dominante des grands principes démocratiques, également les projets politiques en compétition - bref, selon tout un ensamble de paramèters -, un État ou des segments de la société pourrount se rattacher de façon dominante à tel ou tel type de laïcité et/ou mixer plusieurs types (Jean BAUBÉROT; Micheline MILOT, 2011, p. 117).

6 A referida Declaração foi apresentada no Senado francês, no ano de 2005, em ocasião da comemoração de 100 anos da separação entre Igreja Católica e Estado na França. A versão aqui apresentada se encontra em livro organizado por Roberto Arriada Lorea (2009), intitulado Em defesa das liberdades laicas. 
Embora longo, vale destacar de forma integral os artigos 4, 5, 6 e 7 da Declaração já referenciada:

Artigo 4. Definimos laicidade como a harmonização, em diversas conjunturas sócio-históricas e geopolíticas, dos três princípios já indicados: respeito à liberdade de consciência e sua prática individual e coletiva; autonomia política da sociedade civil com relação às normas religiosas e filosóficas particulares; nenhuma discriminação direta ou indireta contra os seres humanos.

Artigo 5. Um processo laicizador emerge quando o Estado não está mais legitimado por uma religião ou por uma corrente de pensamento específica, e quando o conjunto de cidadãos puder deliberar pacificamente, com igualdade de direitos e dignidade, para exercer sua soberania no exercício do poder político. Respeitando os princípios indicados, este processo se dá através de uma relação íntima com a formação de todo o Estado moderno, que pretende garantir os direitos fundamentais de cada cidadão. Então, os elementos da laicidade aparecem necessariamente em toda a sociedade que deseja harmonizar relações sociais marcadas por interesses e concepções morais ou religiosas plurais.

Artigo 6. A laicidade, assim concebida, constitui um elemento chave da vida democrática.

Impregna, inevitavelmente, o político e o jurídico, acompanhando assim os avanços da democracia, o reconhecimento dos direitos fundamentais e a aceitação social e política do pluralismo.

Artigo 7. A laicidade não é patrimônio exclusivo de uma cultura, de uma nação ou de um continente. Poderá existir em conjunturas onde este termo não tem sido utilizado tradicionalmente. Os processos de laicização ocorreram ou podem ocorrer em diversas culturas e civilizações sem serem obrigatoriamente denominados como tal (DECLARAÇÃO, 2009, s/n).

Quando partimos dos elementos pontuados acima, pode-se dizer que entendemos, como pilares fundamentais da laicidade, a garantia da liberdade de consciência dos/as/xs indivíduos (do qual fazem parte a liberdade de crença ou de não crença) e, na medida em que a ordem jurídico-política não é mais determinada e legitimada por uma moral religiosa específica, a laicidade configura-se como o arranjo político que possui como característica central a neutralidade do Estado em matéria 
religiosa, a fim de que este seja o responsável por garantir o respeito à liberdade de consciência, à liberdade de culto para toda e qualquer denominação religiosa e a igualdade entre cidadãs, cidadxs e cidadãos de direito independentemente de crença ou não. Essa neutralidade, entretanto não deve ser confundida meramente como isenção/omissão estatal. A esse respeito, Micheline Milot (2009) salienta que:

O Estado não é representante de uma parcela da sociedade civil nem de maiorias políticas ou circunstanciais, mas sim do conjunto da sociedade. [...] Em nosso ver, o Estado que não intervém para reequilibrar a força política de uma maioria que pode limitar os direitos de minorias, perde de certo modo sua neutralidade, já que não preza por assegurar equitativamente os interesses de todos os cidadãos e por corrigir as desigualdades concretas (Micheline MILOT, 2009, p. 19-20, tradução livre) $)^{7}$.

Nessa compreensão, a neutralidade do Estado em matéria religiosa e como força política garantidora da equidade de direitos e do necessário equilíbrio entre maiorias e minorias sociais, configura-se como elemento necessário para a consolidação de ideais de justiça social e, dessa forma, encontra-se em íntima consonância com os princípios democráticos do Estado de Direito. Falar em neutralidade e em promoção de igualdade, afinal, extrapola os limites que concernem aos direitos garantidos no exercício da vivência religiosa de cidadxs, cidadãs e cidadãos. Falar em laicidade é falar de algo que está além dessas fronteiras e que permeia a totalidade da vida social. Segundo Florence Rochefort (2007), um olhar atento às negociações que envolvem grupos religiosos e Estado e sociedade revela, por exemplo, a centralidade das questões de gênero desde os primeiros anos da laicidade francesa. Segundo Rochefort,

El Estado no es el representante de una de las partes de la sociedad civil ni de las mayorías políticas o circunstanciales, sino más bien del conjunto de la sociedad. [... ] A nuestro parecer, el Estado que no interviene para reequilibrar la fuerza política de una mayoría que puede limitar los derechos de las minorías, pierde en cierto modo su neutralidad, ya que no vela por asegurar equitativamente el interés de todos los ciudadanos y por corregir las desigualdades concretas (Micheline MILOT, 2009, p. 19-20). 
As imbricações entre religião e política são determinantes na construção e organização social e cultural do gênero. Religiões, Estados, nações, grupos sociais estão a desenvolver ou a reforçar ideologias de gênero, por vezes junto, por vezes rivais, mas sempre estreitamente ligadas a escolhas políticas, morais, formas de autoridade, hierarquias, heranças culturais e linhas de divisão sexuada entre a esfera privada e pública (Florence ROCHEFORT, 2007, p. 13) ${ }^{8}$.

Falar em laicidade é falar, também, em questões de gênero. Mais que isso, é pensar em como interesses na manutenção das assimetrias de gênero se colocam em meio às disputas religiosas por espaços na política, tensionando e (re)produzindo formas de desrespeito à laicidade e à democracia, visto que a igualdade de gênero, os direitos das mulheres e os direitos sexuais constituem o eixo central do novo paradigma político-religioso. A respeito dessas posturas de desrespeito, Roberto Blancarte salienta:

[...] a democracia moderna e a laicidade tem elementos comuns de identidade: não pode haver uma laicidade real sem uma democracia constitucional e uma democracia constitucional, para ser de tal maneira completa, requer ser laica. Isso significa que a laicidade não é tampouco uma imposição da vontade absoluta da maioria a toda uma população, mas supõe o respeito dos direitos humanos de todos e em particular o respeito dos direitos das minorias, sejam estas religiosas, étnicas, de gênero, de orientação sexual ou de qualquer tipo. É por isso que a laicidade defende o respeito à liberdade de consciência e a igualdade de todos sem discriminação (Roberto BLANCARTE, 2013, p. 300-301)9.

8 Les imbrications entre le politique et le religieux sont déterminantes dans la construction et l'organisation sociale et culturelle du genre. Religions, États, nations, groupes sociaux développent ou confortent des idéologies de genre, parfois conjointes, parfois concurrentes, toujours étroitement liées à des choix politiques, moraux, des formes d'autorité, de hiérarchies, des héritages culturels et des lignes de partage sexuées entre les sphères privée et publique (Florence ROCHEFORT, 2007, p. 13).

$9 \quad[. .$.$] la democracia moderna y la laicidad tengan elementos comunes de identidad: no puede$ haber una real laicidad sin una democracia constitucional y una democracia, para ser tal de manera cabal, requiere ser laica. Lo anterior significa que la laicidad no es tampoco la imposición absoluta de la voluntad de la mayoría la toda población, sino que supone el respecto de los derechos humanos de todos y en particular el respecto de los derechos de las minorías, sean éstas religiosas, étnicas, de género, por preferencia sexual o de cualquier otro tipo (Roberto BLANCARTE, 2013, p. 300-301). 
Ora, não precisamos ir muito longe para perceber que, ainda nos dias atuais, os princípios da laicidade têm sido alvo de desrespeito no que concerne às questões que envolvem temas morais controversos, notadamente as questões de gênero e sexualidade. Articulações entre religião e política têm sido feitas no sentido de obstaculizar a ampliação dos direitos das mulheres e da população LGBTIQ em diversas partes do mundo. Constatações dessas relações já foram identificadas como um casamento fatal (Shahra RAVAZI; Anne JENICHEN; Jacqueline HEINEN, 2006). E é disso que se trata, quando dizemos que os princípios da laicidade necessitam ser respeitados, pois estão em íntima relação com os direitos de cidadania. Veremos a seguir como essas questões têm sido postas na realidade brasileira.

\section{PARA PENSAR LAICIDADE E DIREITOS SEXUAIS E REPRODUTIVOS NO BRASIL CONTEMPORÂNEO}

As análises subsequentes se concentrarão na forma como os evangélicos têm marcado presença na política institucional brasileira por meio da atividade dos parlamentares que compõem a FPE no Congresso Nacional. Se nos propusermos a falar sobre laicidade no Brasil, devemos considerar condutas que têm se consolidado como ameaças à laicidade e que se tecem na contramão à tentativas de ampliação de direitos de cidadania. No que concerne a isso, os parlamentares evangélicos (mas não só, visto que o posicionamento de parlamentares católicos também deve ser considerado, embora não seja o objetivo deste texto) tem se consolidado como importante grupo de pressão em questões relativas à moral sexual, sobretudo quando falamos em direitos sexuais e reprodutivos. Isso nos faz retomar a um ponto do qual já nos ocupamos: as questões referentes a gênero e sexualidade encontram-se no centro dos debates sobre laicidade, e as relações entre religião e política têm colocado sérios empecilhos à ampliação de direitos de cidadania para mulheres e para a população LGBTIQ.

As problemáticas que envolvem a laicidade e a garantia de direitos nos levam a pensar também sobre as questões concernentes à própria democracia. Já analisamos brevemente como a laicidade tem se constituído como elemento fundamental para o Estado Democrático de 
Direito, mas afinal o que entendemos por democracia? Para esclarecer devidamente os termos, pensamos ser necessário esclarecer, de antemão, o que caracteriza a concepção de democracia em que pretendemos nos apoiar. Desvencilhando-nos da concepção de que a democracia funcionaria como um regime político caracterizado pela vontade da maioria, apostamos em uma definição que admite a possibilidade da pluralidade em todos os campos da vida social: na vida religiosa, nas ideologias políticas, no vasto campo da sexualidade, entre outros. Dessa forma, corroboramos com as proposições de Norberto Bobbio, em sua asserção de que falar em democracia, em contextos pluralistas como o das sociedades contemporâneas, é falar de um regime político que permite a dialética entre dissenso e consenso, sendo esta a sua própria especificidade em relação a outros regimes políticos. É nesse processo dialético que o pluralismo se evidencia. Nas palavras de Bobbio:

O pluralismo enfim nos permite apreender uma característica fundamental da democracia dos modernos em comparação com a democracia dos antigos: a liberdade - melhor: a liceidade - do dissenso [...] o dissenso, desde que mantido dentro de certos limites (estabelecidos pelas denominadas regras do jogo [democrático]), não é destruidor da sociedade, mas solicitador, e uma sociedade em que o dissenso não seja admitido é uma sociedade morta ou destinada a morrer (Norberto BOBBIO, 1986, p. 61).

Ora, falar em um sistema político do dissenso nada mais é que falar sobre um sistema político no qual a diversidade e o pluralismo são a ele inerentes. Mais do que isso, são necessários para que a vida democrática se caracterize como tal. É na concepção de democracia entendida como regime político do dissenso que se coloca em xeque tudo aquilo que se pretende impor como verdade absoluta, e aqui já é pertinente ressaltar a primeira relação que estabelecemos entre democracia, entendida nestes termos, e a questão da laicidade e das religiões no Estado Democrático de Direito.

Saulo Baptista (2013) considera que nas sociedades atuais há certa busca pelas religiões de conserva como forma de suprimir as incertezas trazidas pela modernidade. Para conseguir suprir esse papel de superação das incertezas, essas religiões carregam, em seu escopo teológico, 
verdades absolutas que estabelecem critérios arbitrariamente construídos sobre elementos fundamentais da vida social e definidores, por exemplo, do que é certo e do que é errado. Desse modo, essas verdades absolutas são incapazes de tolerar o dissenso característico dos regimes democráticos. Nas palavras de Baptista:

As religiões não costumam tolerar o dissenso em questões teológicas. Embora a fé seja sempre fundamentada em interpretações, cada instituição religiosa tem uma trajetória histórica, na qual "a verdade" é dada pela exegese e hermenêutica do grupo que detém o poder, no período considerado. Quem tem a hegemonia tem a ortodoxia. Os opositores são sempre hereges. Em contexto dessa natureza, não há clima para alimentar qualquer processo democrático, pois não se limita apenas a regras de governo (Saulo BAPTISTA, 2013, p. 155).

Paradoxalmente, a intolerância para com o dissenso no seio de determinada comunidade religiosa é garantida pelo Estado Democrático de Direito justamente porque a laicidade se manifesta, entre outras formas, na garantia da liberdade religiosa de crença e de culto. Os princípios laicos da não discriminação, e a possibilidade das diferentes formas de produção religiosa de sentido fazem parte, portanto, das garantias de liberdade de consciência sem as quais não poderíamos falar em laicidade.

A relação entre laicidade e garantia de direitos é mais íntima do que se possa pensar e, em todo momento, laicidade, democracia, e cidadania se perpassam mutuamente. Não somente no que concerne às liberdades religiosas como elementos que compõem a liberdade de consciência, mas também no que se refere às garantias de direitos de cidadãs, cidadãos e cidadxs que passam a reivindicar os seus direitos.

Se pensarmos na luta por direitos de cidadania atrelada às transformações sociais no seio de determinado contexto, sem dúvida podemos pensar que alguns direitos de cidadania só foram possíveis de serem reivindicados a partir do momento em que os princípios da laicidade passaram a ser minimamente respeitados ou, ao menos, considerados em sua possibilidade de existência futura. Esta é, sem dúvida, a condição do que entendemos hoje quanto aos direitos sexuais e reprodutivos das mulheres e da população LGBTIQ. Sua reivindicação seria mais facilmente silenciada em contextos nos quais verdades absolutas 
fundamentadas em preceitos religiosos fizessem parte da composição e legitimação do Estado.

Aqui se revela uma de nossas problemáticas centrais: as verdades absolutas fundamentadas em preceitos religiosos ainda fazem parte da composição do Estado que deveria, em contrapartida, garantir os direitos sexuais e reprodutivos através de julgamentos laicos a respeito desses direitos que são fundamentais à dignidade humana. Embora seja necessário pontuar que tais verdades absolutas não existam mais enquanto política institucional intrínseca ao Estado brasileiro e o seu ordenamento jurídico, é inegável que ainda existem porque parlamentares que se autodeclaram religiosos empenham-se dia a dia, em suas atividades legislativas, na tentativa de imposição dessas verdades que, mesmo sem sucesso, obstaculizam e retardam a ampliação de direitos ou retrocedem em direitos já adquiridos, desrespeitando os princípios da laicidade do Estado. Esta tem sido a forma de atuação dos parlamentares evangélicos que compõem a FPE.

A utilização de bandeiras pela defesa de uma configuração heterossexual, cisgênera e monogâmica de família, da militância contra a legalização do aborto em quaisquer circunstâncias (mesmo casos de estupro e anencefalia do feto), os ataques à chamada ideologia de gênero nos debates sobre o Plano Nacional de Educação 2014-2024 e a demonização de tudo o que trate de questões de gênero e sexualidade fora dos moldes de uma moral sexual religiosa e tradicional têm sido os principais alvos da cruzada moral desses parlamentares. Com isso, não estamos afirmando que foram os evangélicos que iniciaram essa empreitada contra reivindicações dos movimentos feminista e LGBTIQ, mas consideramos que os parlamentares evangélicos têm ganhado destaque na política a partir do início do presente século na defesa de pautas que, até meados da década de 1990, eram bandeiras políticas dos segmentos católicos conservadores (mas que ainda são amplamente apoiadas por esse mesmo segmento). Assim, o que ocorre é que, mormente a partir do ano de 2009, os parlamentares evangélicos têm alcançado maior visibilidade na medida em que atuam enquanto lideranças religiosas com certo espaço privilegiado na mídia e, concomitantemente, enquanto legisladores. 
As polêmicas envolvendo políticos evangélicos e as questões dos direitos reprodutivos e da descriminalização do aborto, assim como aquelas relacionadas a direitos sexuais como a criminalização da homofobia e a legalização da união civil entre pessoas do mesmo sexo passaram a ganhar maior visibilidade midiática no ano de 2009, sobretudo a partir do lançamento do Plano Nacional de Direitos Humanos (PNDH-3), e se estenderam para o pleito eleitoral do ano de 2010, pleito esse que marca um primeiro período de destaque da ação política dos evangélicos como grupo de pressão para a manutenção da moral sexual tradicional.

Analisando o processo eleitoral de 2010, Sandra Duarte de Souza (2013) destaca a atuação dos evangélicos enquanto apoiadores ou adversários políticos da então candidata do Partido dos Trabalhadores (PT) à presidência, Dilma Rousseff, os evangélicos procuraram fazer valer os princípios cristãos nos posicionamentos dessa candidata em questões concernentes à descriminalização do aborto e à moral sexual. Grupos evangélicos que apoiaram a candidata, sobretudo as Assembleias de Deus do Ministério Madureira (CONAMAD), fizeram-na estabelecer acordos nos quais exigiam a retirada desses temas morais controversos de pauta em troca de seu apoio eleitoral; seus adversários, por sua vez, encabeçados pela figura do líder assembleiano Silas Malafaia empenharam-se, na demonização da petista, acusando-a da defesa dessas mesmas pautas controversas e declararam apoio público ao principal candidato da oposição, José Serra, do Partido da Social Democracia Brasileira (PSDB). A pressão religiosa fez que a candidata em questão refutasse seus próprios posicionamentos, visto que em ocasiões anteriores salientara ser favorável à descriminalização do aborto, na medida em que entendia essa questão como de saúde pública, e passasse a se posicionar contrariamente à descriminalização do aborto durante a campanha presidencial, recorrendo inclusive a argumentos de cunho moral e, dessa forma, comprometendo a efetiva ampliação dos direitos reprodutivos das mulheres em seu governo após vitória nas urnas. A descriminalização do aborto enquanto aquilo que se refere à saúde e à autonomia dos corpos das mulheres foi utilizada como moeda de troca para o recebimento do apoio de setores religiosos conservadores católicos e evangélicos. De acordo com Sandra Duarte de Souza: 
o[...] das disputas de 2010, talvez o segmento mais vitorioso tenha sido o dos evangélicos, que tiveram seu poder político ampliado por meio do uso político da religião, particularmente da moral sexual religiosa. Dilma foi eleita e os evangélicos estão "cobrando a conta". As questões do aborto, da homofobia e da união civil entre pessoas do mesmo sexo têm sido utilizadas como moeda de troca nas relações de força travadas na arena política brasileira e, ao que tudo indica, continuará sendo nas próximas corridas eleitorais (Sandra Duarte de SOUZA, 2013, p. 199).

A respeito da questão do aborto, por exemplo, o discurso da candidata petista, em poucos meses de campanha, mudou de considerar sua legalização como questão de saúde pública para ganhar tom de questão moral. Como salientam Cristina Vital e Paulo Victor Leite Lopes (2012), “[...] não apenas a vulgarização da discussão do aborto tornou-se um problema, mas o próprio reforço do lugar do religioso (apenas em sua versão cristã) também representa um retrocesso em termos de conquistas políticas desse pleito" (Cristina VITAL; Paulo Victor Leite LOPES, 2012, p. 108).

O modo de fazer política dos evangélicos, seja enquanto legisladores, seja enquanto grupo de pressão presente na sociedade civil brasileira, tem estabelecido de forma muito precisa os inimigos que devem ser combatidos. Segundo Maria das Dores Campos Machado, "o que se percebeu nesse [...] pleito [de 2010] foi a reconfiguração da política dos segmentos religiosos e, mais especificamente, a politização reativa à agenda dos movimentos feminista e LGBT" (Maria das Dores C. MACHADO, 2012, p. 49). Entretanto, as iniciativas de parlamentares evangélicos no que se refere à questão do aborto não se restringem somente em pressionar o poder executivo ou os candidatos a esse cargo, mas também se configuram na atuação destes em várias Frentes Parlamentares antiabortistas (Frente Parlamentar da Família e Apoio à Vida, Frente Parlamentar em Defesa da Vida - Contra o Aborto etc.) e em Projetos de Lei, a exemplo do PL 5069/2013 de autoria do ex-deputado federal e membro da FPE, Eduardo Cunha (PMDB-RJ), que tipifica como crime a ser prescrito no Código Penal, sob o artigo 127-A, o "anúncio de meio abortivo ou induzimento ao aborto". A justificativa do projeto coloca-se contra superpotências capitalistas e agências internacionais 
que supostamente financiariam o movimento feminista ${ }^{10}$. Tais afirmações baseiam-se em posicionamento de setores da Igreja Católica com relativos à IV Conferência Mundial Sobre a Mulher: Igualdade, Desenvolvimento e Paz, realizada pela Organização das Nações Unidas (ONU), em 1995, e explicitados em carta da Conferência Episcopal Peruana contra a chamada ideologia de gênero"1, no qual caracterizam as feministas como, além de neomarxistas, meretrizes financiadas por organizações e superpotências capitalistas (CONFERÊNCIA EPISCOPAL PERUANA, 1998).

As formas como as questões de gênero estão no centro dos debates que se referem à laicidade brasileira na contemporaneidade também são perceptíveis nas respostas da FPE quando se colocam em disputa os direitos das pessoas LGBTIQ, alocados na categoria dos direitos sexuais.

No que se refere à criminalização da homofobia, o Projeto de Lei da Câmara PLC 122/2006, os argumentos utilizados pelos parlamentares evangélicos e por grupos evangélicos no geral são relativos à liberdade de tratar a homossexualidade (ou homossexualismo, expressão mais comumente utilizada por esse grupo) como pecado condenável aos olhos de Deus. Ao se colocarem em postura de desafio à laicidade brasileira, usam como recurso de argumentação algo que é característico deste mesmo elemento: o apelo à liberdade religiosa. Perpassando debates de mesas-redondas que ocorreram na Câmara dos Deputados acerca do PLC 122/2006, Natividade e Lopes (2009) salientam argumentos empregados por religiosos que colocam a Bíblia Sagrada acima da Constituição Federal e que se colocam enquanto defensores da família e da lei natural. Além disso, de acordo com os mesmos autores, outra direção tomada pelos argumentos utilizados pelos parlamentares evangélicos (e também católicos), é a de que:

10 BRASIL. Congresso Nacional. Projeto de Lei PL 5069/2013. Acrescenta o artigo 127-A ao Decreto-Lei n. 2.848, de 7 de dezembro de 1940 - Código Penal. Disponível em: <http://www.camara. gov.br/proposicoesWeb/prop_mostrarintegra;jsessionid=A8A2EB98B443200640F395CD4BAC DBA7.proposicoesWeb2?codteor=1061163\&filename=PL+5069/2013>. Acesso em: 20 jun. 2016.

11 Para uma análise pormenorizada do conteúdo da carta da Conferência Episcopal Peruana, ver: Naira Pinheiro dos SANTOS, Fernanda M. Feitosa COELHO (2016). 
[...] a "propagação do homossexualismo" constituía um dos temores: a inclusão do termo [discriminação por] orientação sexual na Constituição poderia significar a "oficialização do homossexualismo", o que deveria ser combatido visto que a homossexualidade é nociva à sociedade, à moral e aos bons costumes, não devendo, portanto, receber apoio sob forma de lei (Marcelo NATIVIDADE; Paulo Victor Leite LOPES, 2009, p. 79).

O recurso ao argumento da liberdade religiosa ganha força especialmente quando se reivindica a liberdade de pregar contra o homossexualismo e de auxiliar aqueles, aquelas e aquelxs que dessa prática queiram se livrar. Segundo Natividade e Lopes (2009), são "argumentos morais que desqualificam a homossexualidade e fundamentam o proselitismo religioso em torno da necessidade de se conter a aceitação social desse comportamento" (Marcelo NATIVIDADE; Paulo Victor Leite LOPES, 2009, p. 81). A contrariedade ao PLC 122/2006 é reforçada, ainda, por ações legislativas como o Projeto de Decreto Legislativo 234/2011, de autoria do deputado federal e presidente da FPE, João Campos (PSDB-GO) e que versa sobre o que se culminou chamar cura gay. O referido projeto, em nome da liberdade religiosa e na tentativa de deslegitimar as sexualidades que fogem aos padrões socialmente estabelecidos, prevê sustar os artigos $3^{\circ}$. e $4^{\circ}$. do Conselho Federal de Psicologia, de forma a permitir tratamentos de reversão do homossexualismo para quem assim o desejasse ${ }^{12}$. Os debates em torno desse assunto ganharam novamente os holofotes da mídia brasileira no ano de 2017, quando o juiz Waldemar Cláudio de Carvalho, do Distrito Federal, concedeu uma liminar que pode dar brechas para esse tipo de "tratamento" psicológico.

A retórica dos parlamentares que compõem a FPE no que concerne às homossexualidades (e também às transexualidades) é de constantes tentativas de desqualificação das formas de expressão da sexualidade e das performances de gênero (Judith BUTLER, 2015) que fogem à he-

12 BRASIL. Congresso Nacional. Projeto de Decreto Legislativo PDC 234/2011. Susta a aplicação do parágrafo único do Artigo $3^{\circ}$. e o Artigo $4^{\circ}$., da Resolução do Conselho Federal de Psicologia $n^{\circ}$. $1 / 99$ de 23 de março de 1999, que estabelece normas de atuação para os psicólogos em relação à questão da orientação sexual. Disponível em: <http://www.camara.gov.br/proposicoesWeb/ prop_mostrarintegra?codteor=881210\&filename=PDC+234/2011>. Acesso em 20 jun. 2016. 
teronormatividade, e em todo momento se faz presente a tentativa de caracterizá-las como ilegítimas em detrimento da heterossexualidade social e religiosamente legitimada. Isto pode ser novamente verificado nos posicionamentos desses parlamentares em relação à união civil e ao casamento entre pessoas do mesmo sexo ou então em proposições legislativas que reiteram que somente as formas tradicionais são legítimas. Este também tem sido o caso dos debates em torno da concepção de família, representado principalmente pelo PL 6583/2013, o Estatuto da Família, proposto pelo deputado federal e membro da FPE, Anderson Ferreira (PR-PE), aprovado em Comissão Especial na Câmara dos Deputados no ano de 2015. O referido projeto coloca-se em clara oposição ao Supremo Tribunal Federal, no ano de 2011, que reconheceu a união homoafetiva como entidade familiar. Em análise a respeito da defesa da família como uma das principais bandeiras desses parlamentares, Tainah Biela Dias salienta:

Apostando numa família ontológica, na "obviedade" da família heterossexual como única correta por atender aos propósitos divinos da procriação e da perpetuação da espécie, tais discursos negligenciam, de forma propositada, todo e qualquer componente histórico que revele as transformações sofridas daquilo que conhecemos como família. Desta forma, a invocação de uma ontologia da família esconde registros históricos de uma pluralidade inegável de arranjos familiares nas sociedades não Ocidentais e não cristãs (Tainah Biela DIAS, 2017, p. 93-94).

Ora, quando os parlamentares evangélicos invocam discursos sobre uma família tradicional brasileira como uma das principais bandeiras de defesa da FPE nos dias atuais, implicitamente excluem e privam de direitos toda uma diversidade de configurações familiares já existentes e, entre elas, aquelas compostas por casais de pessoas do mesmo sexo. Apenas com o intuito de dar concretude à percepção dessa diversidade, vale salientar que os dados do Censo de 2010 identificaram nove diferentes tipos de composição familiar, sendo que a família tradicional, entendida como o núcleo formado por um homem, uma mulher e seus filhos, caiu de $56,4 \%$ no ano de 2000 para $49,4 \%$ em 2010 no que corresponde ao total de famílias da amostra (IBGE, 2010). 
As transexualidades também são foco da ação desses parlamentares. No ano de 2015, por exemplo, pudemos observar algumas tensões do toalete, quando a Secretaria de Direitos Humanos da Presidência da República publicou uma resolução $n^{\circ}$. 12/2016 que, entre outras coisas, preconizava que as pessoas travestis e transexuais deveriam ter seu acesso e permanência em diferentes espaços sociais garantidos. Entre esses espaços, o Artigo $6^{\circ}$. prevê que: "deve ser garantido o uso de banheiros, vestiários e demais espaços segregados por gênero, quando houver, de acordo com a identidade de gênero de cada sujeito" (BRASIL, 2015a, p. 51). Menos de uma semana após a publicação da resolução, o deputado Pastor Marco Feliciano (PSC-SP) manifestou-se, lançando um Projeto de Decreto Legislativo que pretendia sustá-la. Além disso, pronunciou-se na Câmara dos Deputados, dizendo que o "País passa por uma pequena atribulação de pensamentos com relação à questão da moralidade", pois aquilo seria "um incentivo àquilo que não sei dizer o que é" (BRASIL, 2015b, p. 61, grifos da autora). Ora, a fala do deputado demonstra não só uma tentativa de retroceder em um direito adquirido pelas pessoas travestis e transexuais de utilizar os banheiros de acordo com sua identidade de gênero, mas também uma forma de entender a divisão entre homem e mulher baseando-se única e exclusivamente no sexo biológico de nascimento desses sujeitos, e do qual a divisão de banheiros definida pelo órgão genital é uma das maneiras mais explícitas da operacionalização dessa lógica que é compartilhada pela sociedade quase que de forma hegemônica, por meio de construções culturais enraizadas socialmente e que fazem da heterossexualidade cisgênera uma norma determinada aos sujeitos com base no seu sexo de nascimento.

As proposições já analisadas demonstram algumas das formas pelas quais a FPE tem agido de modo militante na tentativa de obstaculizar tudo aquilo que se configure como ameaça às suas concepções de identidades de gênero e sexualidades entendidas corretas, seja em campanhas eleitorais, audiências públicas, Projetos de Lei, entre outros. Percebemos, então, que o que se constrói na atuação desses parlamentares são discursos de verdade (Michel FOUCAULT, 1999, 2014, 2015) sobre a família, acerca das sexualidades e a respeito das identidades de gênero que justificam a ação desses sujeitos na tentativa de impo- 
sição, por meio da regulação jurídica e da forma como estes atuam no legislativo, suas concepções particulares e religiosamente formuladas.

O intuito dos parlamentares evangélicos em normalizar e regular os corpos das mulheres e da população LGBTIQ coloca-se, portanto, contrário à ampliação dos direitos sexuais e reprodutivos. Além disso, foge àquilo que entendemos por democracia como regime político que permite o dissenso, na medida em que procura impor uma concepção de família restrita a determinada parcela da população como verdade absoluta. As empreitadas militantes dessa bancada na tentativa de imposição de sua própria moral sexual traz desafios aos arranjos políticos da laicidade do Estado brasileiro, pois cristaliza a segregação sofrida pelas mulheres e pelas pessoas LGBTIQ na proporção em que parlamentares que se autodenominam evangélicos realizam, segundo Sandra Duarte de Souza (2013), um uso político do sexo. Ainda, de acordo com essa autora, esses parlamentares:

[...] [utilizam] o recurso à palavra autorizada [...]. Os políticos evangélicos têm tomado para si o papel de reguladores da sexualidade em nome de Deus. O argumento religioso apresenta-se como legítimo por si mesmo. Uma verdade supostamente universal que não admite quaisquer questionamentos (Sandra Duarte de SOUZA, 2013, p. 191).

Como vimos nas reflexões já realizadas, a garantia dos princípios da laicidade e a possibilidade de convivência de pluralidades dissonantes é colocada em xeque quando há tentativas de imposição. Nesse caso, imposição de uma moral sexual em que as questões de gênero e sexualidade estão no centro da disputa (Florence ROCHEFORT, 2007).

\section{CONSIDERAÇÕES FINAIS}

O presente artigo buscou analisar como se tecem as relações entre religião e política no Brasil, tendo como objetivo analisar as formas pelas quais a atuação recente de parlamentares que se autodenominam evangélicos têm se configurado como ameaças à laicidade brasileira, na medida em que colocam obstáculos à ampliação dos direitos sexuais e reprodutivos das mulheres e da população LGBTIQ. Para isso, 
procuramos esclarecer que a concepção de laicidade está relacionada à noção de cidadania e de democracia, visto que esta busca assegurar a pluralidade e o respeito às diversidades.

Demonstramos como esses parlamentares utilizam diversos mecanismos, seja enquanto legisladores, ou enquanto lideranças religiosas com grande poder de influência sobre candidatos à presidência da República, na tentativa de impor sua própria moral sexual a toda a sociedade brasileira, sobrepondo aqueles, aquelas e aquelxs que não se conformam aos seus padrões de sexualidade e identidade de gênero aos seus próprios valores.

Estas discussões não se findam aqui. É importante ressaltar que as mesmas questões levantadas no decorrer deste texto continuam sendo centrais nos debates que envolvem gênero e sexualidades no Congresso Nacional. A força (re)adquirida pelos conservadorismos nos últimos anos potencializou-se após o sucesso do questionável impeachment que destituiu a presidenta Dilma Rousseff, no ano de 2016, e escancarou as portas para que temas que violam a dignidade humana de mulheres e pessoas LGBTIQ obtivessem maior facilidade de aprovação.

Recentemente, exposições como as do Queermuseu foram fechadas, uma peça que apresentava Jesus reencarnado em uma mulher transexual foi objeto de censura e houve a tentativa de criminalizá-la. Fora isso, novos Projetos de Lei criados para proibir que a ideologia de gênero fizesse parte dos Planos Municipais de Educação também protagonizaram calorosos debates. Tudo isso apenas para corroborar com a afirmação de que as questões de gênero têm primazia nos debates acerca da laicidade no Brasil contemporâneo.

Assim, este artigo se finda com um apelo para a necessidade do aprofundamento das discussões sobre como a importância do respeito aos princípios da laicidade é imprescindível quanto perigosa para aqueIxs, aquelas e aqueles que se colocam em defesa de uma sociedade pluralista, democrática e que respeite a condição de cidadãs, cidadãos e cidadxs. 


\section{REFERÊNCIAS}

BAPTISTA, Saulo de T. C. Religião e Democracia. Estudos de Religião, v. 27, n. 1, 2013, p. 138-156.

BAUBÉROT, Jean; MILOT, Micheline. Laïcité sans frontières. Paris: Seuil, 2011.

BERGER, Peter Ludwig. A dessecularização do mundo: uma visão global. Religião e Sociedade. Rio de Janeiro, v. 21, n. 1, 2000, p. 9-24.

BERGER, Peter Ludwig. O dossel sagrado: elementos para uma teoria sociológica da religião. São Paulo: Paulus, 1985.

BLANCARTE, Roberto (Coord.). Las leyes de reforma y el Estado laico: importancia histórica y validez contemporánea. México: El Colegio de México, Centro de Estudios Sociológicos, 2013.

BOBBIO, Norberto. O futuro da democracia: uma defesa das regras do jogo. Rio de Janeiro: Paz e Terra, 1986.

BRASIL. Congresso Nacional. Projeto de Decreto Legislativo PDC 234/2011. Susta a aplicação do parágrafo único do Art. $3^{\circ}$ e o Art. $4^{\circ}$, da Resolução do Conselho Federal de Psicologia $n^{\circ} 1 / 99$ de 23 de Março de 1999, que estabelece normas de atuação para os psicólogos em relação à questão da orientação sexual. Disponível em: <http://www. camara.gov.br/proposicoesWeb/prop_mostrarintegra?codteor $=881210$ \&filename $=P$ DC+234/2011>. Acesso em 20 jun. 2016.

BRASIL. Congresso Nacional. Projeto de Lei PL 5069/2013. Acrescenta o art. 127-A ao Decreto-Lei no. 2.848, de 7 de dezembro de 1940 - Código Penal. Disponível em: <http:// www.camara.gov.br/proposicoesWeb/prop_mostrarintegra;jsessionid=A8A2EB98B4432 00640F395CD4BACDBA7. proposicoesWeb2? codteor=1061163\&filename=PL+5069/2013>. Acesso em: 20 jun. 2016.

BRASIL. Congresso Nacional. Projeto de Lei PL 6583/2013. Dispõe sobre o Estatuto da Família e dá outras providências. Disponível em: <http://www.camara.gov.br/proposicoesWeb/fichadetramitacao?idProposicao=597005>. Acesso em 20 jun. 2016.

BRASIL. Diário da Câmara dos Deputados, 15 abr. 2015b.

BRASIL. Resolução n 12, de 2015. Estabelece parâmetros para a garantia das condições de acesso e permanência de pessoas travestis e transexuais - e todas aquelas que tenham sua identidade de gênero não reconhecida em diferentes espaços sociais - nos sistemas e instituições de ensino, formulando orientações quanto ao reconhecimento institucional da identidade de gênero e sua operacionalização. Diário Oficial, Brasília, DF, 12 mar. 2015a, Seção 1, p. 3.

BRASIL. Secretaria de Direitos Humanos da Presidência da República. Programa Nacional de Direitos Humanos (PNDH 3). Secretaria de Direitos Humanos da Presidência da República: Brasília, 2010. 
BUTLER, Judith. Problemas de gênero: feminismo e subversão da identidade. Rio de Janeiro: Civilização Brasileira, 2015.

CONFERÊNCIA EPISCOPAL PERUANA. A ideologia de gênero: seus perigos e alcances. Lima, Peru, 09 de junho de 2008. Disponível em: <http://img.cancaonova.com/noticias/ pdf/281960_IdeologiaDeGenero_PerigosEAlcances_ConferenciaEpiscopalPeruana.pdf >. Acesso em: 9 nov. 2016.

COSTA, Néstor da (Org.). Laicidad en América Latina y Europa: repensando lo religioso entre lo público y lo privado en el siglo XXI. Montevideo: CLAEH, 2006.

DECLARAÇÃO universal da laicidade no século XXI. In: LOREA, Roberto Arriada (Org.). Em defesa das liberdades laicas. Porto Alegre: Livraria do Advogado, 2009, s/n.

DIAS, Tainah Biela. Sobre Religião, Estado Laico e Cidadania LGBT+: a Frente Parlamentar Evangélica e a defesa da verdade sobre a família. 2017. 147p. Dissertação de Mestrado (Ciências da Religião). Universidade Metodista de São Paulo, São Bernardo do Campo, 2017.

FOUCAULT, Michel. A ordem do discurso. São Paulo: Loyola, 1999.

FOUCAULT, Michel. História da sexualidade: a vontade de saber. São Paulo: Paz e Terra, 2014.

FOUCAULT, Michel. Microfísica do poder. São Paulo: Paz e Terra, 2015.

GIUMBELLI, Emerson. A presença do religioso no espaço público: modalidades no Brasil. Religião e Sociedade, Rio de Janeiro, v. 28, n. 2, 2008, p. 80-101.

GIUMBELLI, Emerson. Para estudar a laicidade, procure o religioso. In: BÉLIVEAU, Veronica G.; GIUMBELLI, Emerson (Orgs.). Religión, cultura y política en las sociedade del siglo XXI. Buenos Aires: ACSRM/Biblos, 2013, p. 43-68.

IBGE (Instituto Brasileiro de Geografia e Estatística). Censo demográfico 2010: Famílias e domicílios. Resultados da Amostra, Rio de Janeiro, 2010.

MACHADO, Maria das Dores Campos. Aborto e ativismo religioso nas eleições de 2010. Revista Brasileira de Ciência Política, Brasília, n. 7, 2012, p. 25-54.

MARIZ, Cecília Loreto. Secularização e dessecularização: comentários a um texto de Peter Berger. Religião e Sociedade, Rio de Janeiro, v. 21, n. 1, 2000, p. 25-39.

MILOT, Micheline. La laicidad. Madrid: Editorial CCS, 2009.

NATIVIDADE, Marcelo; LOPES, Paulo Victor Leite. Os direitos das pessoas GLBT e as respostas religiosas: da parceria civil à criminalização da homofobia. In: DUARTE, Luiz Fernando Dias (et al.). Valores religiosos e legislação no Brasil: a tramitação de projetos de lei sobre temas morais controversos. Rio de Janeiro: Garamond, 2009, p. 71-99. PIERUCCI, Antônio Flávio. Secularização em Max Weber: da contemporânea serventia de voltarmos a acessar aquele velho sentido. Revista Brasileira de Ciências Sociais, São Paulo, v. 13, n. 37, 1998, p. 43-73. 
RAZAVI, Shahra, JENICHEN, Anne et HEINEN, Jacqueline. Mariage fatal entre religion et politique: source d'écueils pour l'égalité des sexes. In: FOUGEYROLLAS-SCHWEBEL, Dominique; VARIKAS, Eleni (Orgs.). Cahiers du Genre: Féminisme(s), Recompositions et Mutations. Paris: L'Harmattan, 2006, p. 5-26.

ROCHEFORT, Florence (dir.). Le pouvoir du genre: laïcités et religions 1905-2005. Toulouse: Presses Universitaires du Mirail, 2007.

SANTOS, Naira Pinheiro dos; COELHO, Fernanda Marina Feitosa. A mobilização católica contra a "ideologia de gênero" nas tramitações do Plano Nacional de Educação brasileiro. Religare, v. 13, n. 1, p. 27-48, 2016.

SOUZA, Sandra Duarte. Política religiosa e religião política: os evangélicos e o uso político do sexo. Estudos de Religião, v. 27, n. 1, 2013, p. 177-201.

VITAL, Christina; LEITE, Paulo Victor Lopes. Religião e política: uma análise da atuação de parlamentares evangélicos sobre direitos das mulheres e de LGBTs no Brasil. Rio de Janeiro: Fundação Henrich Böll, 2012.

WEBER, Max. A ética protestante e o "espírito" do capitalismo. São Paulo: Companhia das Letras, 2004.

WEBER, Max. Economia e sociedade: fundamentos da sociologia compreensiva - volume II. Brasília: UnB, 1999.

WEBER, Max. Ensaios de sociologia. Rio de Janeiro: LTC, 1982.

Submetido em: 16-10-2017

Aceito em: 13-11-2017 